\title{
Mapania multiflora, a distinctive new species of Cyperaceae (Mapanioideae) from Borneo
}

\author{
Z. Shabdin ${ }^{1,2}$, A. Culham ${ }^{1}$, D. A. Simpson ${ }^{3}$ \& K. Meekiong ${ }^{2}$
}

Summary. Mapania multiflora is described and illustrated. It is vegetatively similar to taxa with broad leaves and pseudopetioles, such as M. cuspidata. However, it is reproductively similar to sect. Thoractostachyum with a paniculate inflorescence and furrowed fruit. The DNA is similar to M. bancana in sect. Thoractostachyum, in the three sampled cpDNA regions: atpH-F, trnL-F and $p s b A-t r n H$. However, it is identical to none of these due to its unique combination of vegetative, reproductive and molecular characteristics.

Key Words. conservation, Hypolytreae, taxonomy.

\section{Introduction}

The cosmopolitan sedge family Cyperaceae is the third-largest family in the monocots, after orchids and grasses, with 106 genera and c. 5400 species (Govaerts et al. 2007). A wide variety of habitats are occupied by sedges, from swamps to sand-dunes and tropical forests to high arctic tundra (Smith et al. 2009). Several species are ubiquitous weeds which occur in a variety of environments, others are endemic, narrowly distributed and of conservation concern (Naczi \& Ford 2008). The family Cyperaceae comprises two subfamilies, Mapanioideae and Cyperoideae (Simpson et al. 2007; Muasya et al. 2009). Two tribes are assigned under Mapanioideae, namely Hypolytreae and Chrysitricheae. Mapania Aubl., a genus in tribe Hypolytreae contains a group of mostly forestdwelling sedges which are widely distributed throughout the tropics (Simpson 1996). Borneo and Peninsular Malaysia are considered to be centres of diversity for Mapania with 25 and 16 species recorded respectively (Simpson 1992) and new species continue to be discovered (Shabdin et al. 2013). Fifty percent of the species in Borneo are endemic.

During fieldwork in Batu Berkarang, Limbang, northern Sarawak, specimens of Mapania were collected which did not match the morphology of any of the previously described species. There is little information on reproduction, breeding behaviour or population biology of Mapania on which biological species might be based. Therefore we describe a new species based on its distinctions under the morphological/taxonomic species concepts (Cronquist 1978) and in its sampled DNA sequences.

\section{Materials and methods}

MORPHOLOGY. Macromorphological features were recorded using a conventional ruler calibrated in millimetres. Dissections of inflorescence parts were made by soaking an inflorescence in warm water in a Petri dish for 5 - 10 minutes, transferring it to a white glazed tile and then carefully teasing out the parts using mounted needles under a Leica Microsystems S6D binocular photomicroscope. Microscopic features were recorded using a calibrated eyepiece graticule in the microscope and also photographed. Data were recorded into a Microsoft Excel® spreadsheet.

DNA SEQUENCING. Total DNA was extracted from material collected in silica gel (Table 1). The modified CTAB method of Doyle \& Doyle (1987) was used but extractions were precipitated in isopropanol for one week. The $\operatorname{trn} L-F$ intergenic spacer, together with the psbA-trnH and atpH-F plastid genes were each amplified as one complete piece using the following forward and reverse

\footnotetext{
Accepted for publication 30 October 2013. Published online 5 December 2013

1 Centre for Plant Diversity and Systematics, School of Biological Sciences, University of Reading, Reading, RG6 6AS, UK. e-mail: a.culham@reading.ac.uk

2 Department of Plant Science and Environmental Ecology, Faculty of Resource Science Technology, Universiti Malaysia Sarawak, 94300 Kota Samarahan, Sarawak, Malaysia.

3 Herbarium, Royal Botanic Gardens, Kew, Richmond, Surrey, TW9 3AB, UK.
} 